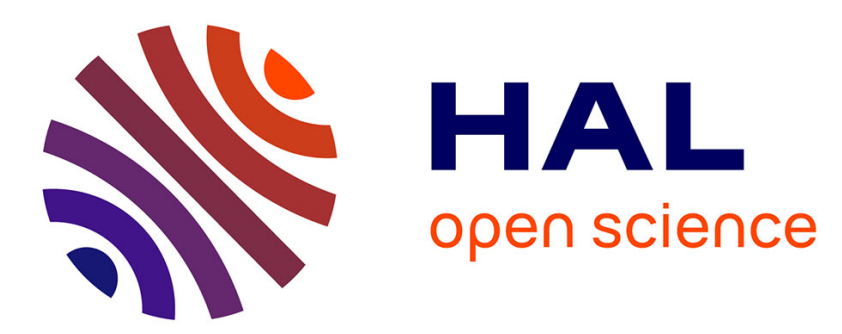

\title{
Dynamique sédimentaire en baie de Wissant (Pas-de-Calais)
}

\author{
Olivier Cohen, Franck Dolique, Vincent Sipka
}

\section{To cite this version:}

Olivier Cohen, Franck Dolique, Vincent Sipka. Dynamique sédimentaire en baie de Wissant (Pasde-Calais). Méditerranée: revue géographique des pays méditerranéens, 1999, 93 (4), pp.78. 10.3406/medit.1999.3142 . hal-02542776

\section{HAL Id: hal-02542776 \\ https://hal.science/hal-02542776}

Submitted on 8 Feb 2021

HAL is a multi-disciplinary open access archive for the deposit and dissemination of scientific research documents, whether they are published or not. The documents may come from teaching and research institutions in France or abroad, or from public or private research centers.
L'archive ouverte pluridisciplinaire HAL, est destinée au dépôt et à la diffusion de documents scientifiques de niveau recherche, publiés ou non, émanant des établissements d'enseignement et de recherche français ou étrangers, des laboratoires publics ou privés. 


\section{Dynamique sédimentaire en baie de Wissant (Pas-de-Calais)}

Monsieur Olivier Cohen, Franck Dolique, Vincent Sipka

\section{Citer ce document / Cite this document :}

Cohen Olivier, Dolique Franck, Sipka Vincent. Dynamique sédimentaire en baie de Wissant (Pas-de-Calais). In: Méditerranée, tome 93, 4-1999. Dynamiques naturelles et gestion des espaces littoraux. p. 78;

doi : https://doi.org/10.3406/medit.1999.3142

https://www.persee.fr/doc/medit_0025-8296_1999_num_93_4_3142

Fichier pdf généré le 25/04/2018 


\title{
Dynamique sédimentaire en baie de Wissant (Pas-de-Calais)
}

\author{
Olivier COHEN* \\ Franck DOLIQUE** \\ Vincent SIPKA*
}

La baie de Wissant, située dans le département du Pas-de-Calais, s'ouvre sur le détroit du même nom. Elle est délimitée par deux caps rocheux : à l'ouest, le cap Gris Nez et au nord-ouest, le cap Blanc Nez. Le fond de cette baie est bordé par une plage et un cordon dunaire, orientés OSO-ENE, longs de sept kilomètres environ. Ce rivage évolue dans un contexte macrotidal (le marnage moyen de vive-eau est de $7 \mathrm{~m}$ ) et de tempêtes à fetch limité, mais ponctuellement très actives.

Cette baie est l'un des rivages français qui reculent le plus rapidement depuis la fin de la Seconde Guerre mondiale. Selon les secteurs, le recul annuel moyen a été estimé de 2 à $7 \mathrm{~m} / \mathrm{an}$. Les parties occidentale et centrale de la baie (dunes de la Baraque Fricot, du Châtelet et d'Aval) sont les plus touchées; elles présentent une morphologie de falaise d'érosion dunaire et très dégradée par des siffle-vents et des caoudeyres, la végétation que l'on trouve classiquement en arrière dune (argousiers, sureaux) dépérit aujourd'hui en haut de plage. L'érosion est telle ici que les bancs de tourbe sous-jacents au sable affleurent largement en milieu de plage. Plus à l'est, devant le village de Wissant, on se trouve en situation d'équilibre fragile (le front d'érosion se déplace vers l'est) et, le long de la dune d'Amont, en situation d'accrétion.

- Cette situation peut s'expliquer par des transferts de sédiments parallèles à la côte, générés d'une part par une résultante de courant dirigée vers le NE (courants de marée et action des houles). En l'absence de mesures hydrodynamiques, cela peut être cependant prouvé par

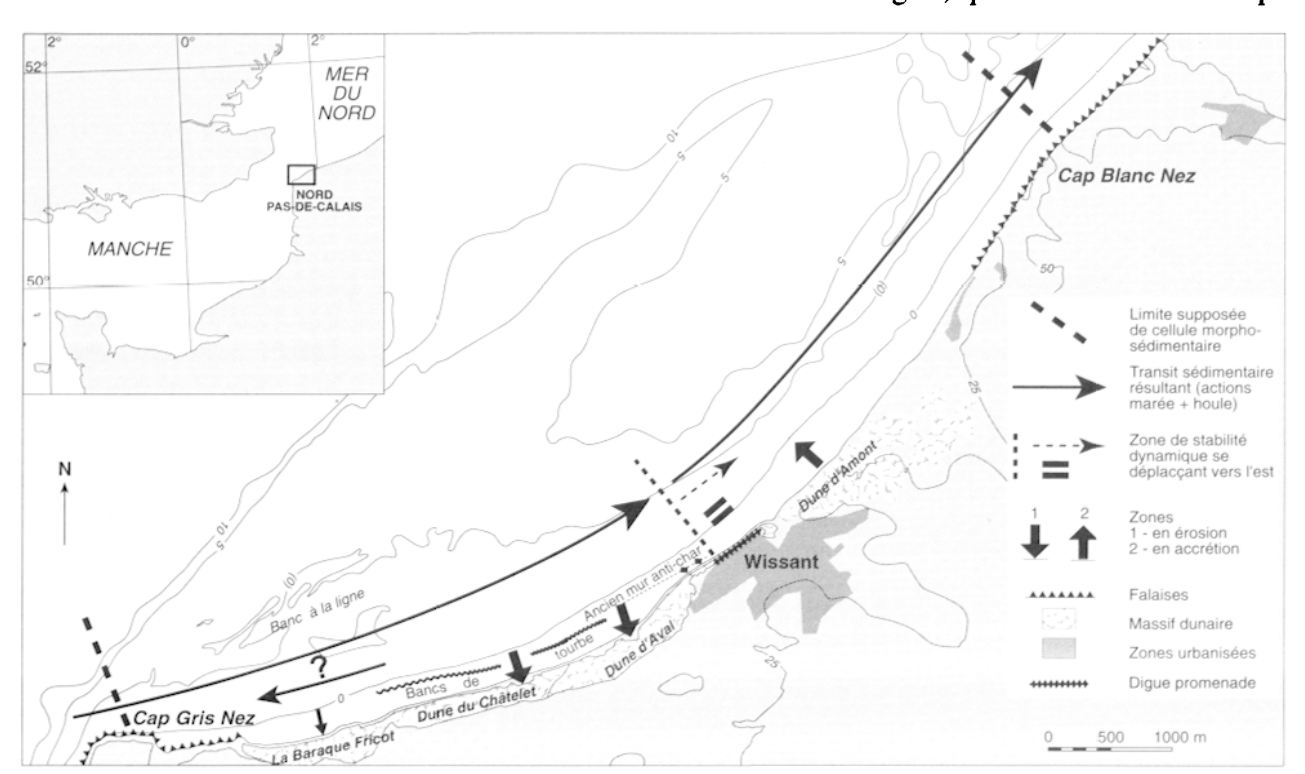

FIG. 1 - ESSAI DE CARTOGRAPHIE DE LA CELLULE MORPHOSÉDIMENTAIRE DE LA BAIE DE WISSANT (D'après V. SIPKA, 1997) des figures sédimentaires de type mégarides, ondulées et asymétriques, en mouvement vers le NE, dont les dimensions sont variables, mais qui restent cependant toujours très massives et plus marquées en période de tempête (leur hauteur peut atteindre plusieurs dizaines de centimètres et leur largeur plusieurs mètres). Ces mouvements de sédiment sont dus d'autre part aux vents dominants de secteur ouest pour le transport éolien. Ce transit sédimentaire résultant provoque, devant la dune d'Amont, l'édification d'un prisme sableux de haut et mi-plage, plus souvent hors d'eau que le reste de la baie et servant de surface de déflation éolienne, de zone source pour l'accrétion de la dune adjacente. Nos levés de profils topographiques montrent que l'estran de la partie centrale de la baie (dunes d'Aval et du Châtelet), la plus érodée, est nettement surbaissé par rapport à l'estran dans le reste de la baie, ce qui explique que les vagues puissent y agir plus longtemps (érosion et transport).

La dynamique actuelle est donc caractérisée par un bilan sédimentaire global déficitaire et un transfert du stock sableux vers le NE. Les études historiques précédemment réalisées s'accordent sur l'existence d'oscillations dans le rythme de recul du rivage ; elles ne déterminent cependant ni les causes ni la date du début de cette phase d'érosion. Ces oscillations seraient à mettre en relation d'une part avec la variabilité des événements météomarins (une fréquence et une intensité s'accroissant) et d'autre part avec celles des bancs sableux immergés et submergeant au large (notamment le Banc à la Ligne) qui réfractent et dissipent les vagues incidentes et, en l'absence de tout apport fluviatile, servent de source de sédiment au rivage. Le démaigrissement du Banc à la Ligne, pendant les vingt dernières années, pourrait ainsi expliquer en partie la situation actuelle, tout comme l'e $\mathrm{ng}$ ra is se men t observé aujourd'hui pourrait permettre de comprendre le ralentissement de l'érosion dans le secteur occidental de la baie. Des études plus poussées ont débuté afin de confirmer ces hypothèses.

*Laboratoire Géomorphologie dynamique et aménagement des littoraux JE 2208 MENESR, Université du Littoral Côte d'Opale, Dunkerque.

**Université de Champagne-Ardenne, Département de Géographie, Reims. 